\title{
Survey of delivery of prophylactic immunoglobulins following exposure to a measles case
}

A Bernier (adeline.bernier@ens.fr) ${ }^{1}$, C Le Goaster ${ }^{1}$, H Peigue-Lafeuille ${ }^{1,2,3}$, D Floret Fl, $^{1,4}$

1. Haut Conseil de la Santé Publique (French High Council for Public Health), Paris, France

2. University Hospital Centre CHU Clermont-Ferrand, Virology Laboratory, Centre of Biology, Clermont-Ferrand, France

3. University of Auvergne, Virology Laboratory, Faculty of Medicine, Clermont-Ferrand, France

4. University Claude Bernard Lyon1- Hôpital Femme Mère Enfant, Bron, France

VBernier A, Le Goaster C, Peigue-Lafeuille H, Floret D. Survey of delivery of prophylactic immunoglobulins following exposure to a measles case. Euro Surveill. 2012;17(39): $\mathrm{pii}=20280$. Available online: $\mathrm{http}: / /$ www.eurosurveillance.org/ViewArticle. aspx? Articleld $=20280$

In France, almost 23,000 cases of measles and 10 deaths have been reported between January 2008 and August 2012. French health authorities recommend delivery of human polyvalent immunoglobulins in the event of exposure to a measles case for some categories of unvaccinated persons (children under the age of 12 months, immunocompromised persons and pregnant women), within six days after exposure and following laboratory confirmation of the contact case. We carried out a postal survey among 368 French hospital pharmacies to evaluate the number of persons affected by this measure between 1 January 2010 and 31 August 2011, to describe the characteristics of these patients and to evaluate the application of the recommendations in terms of delay between exposure and immunoglobulin delivery, and confirmation of the contact case. The response rate to the survey was $73 \%$. In total, 400 immunoglobulin deliveries were listed, most of them for children under the age of one year, and $84 \%$ of the 250 administrations with available information occurred within six days after exposure, as recommended. However, only $48 \%$ of the 209 treated contacts with available information were laboratory-confirmed when the immunoglobulins were delivered. This survey is the first evaluation of this recommendation since its introduction in 2005 and suggests that the recommendations may need to be updated.

\section{Introduction}

Measles is a highly contagious illness, characterised by a rash associated with a cough and fever $\left(>38^{\circ} \mathrm{C}\right)$. The disease is often mild, but serious complications can occur, mainly pneumonia and encephalitis, leading in some cases to death. These complications occur more frequently in children younger than one year and in adults older than 20 years [1-3].

In France, a single-dose vaccination against measles was introduced in 1983, and in 1997, recommendations increased to two doses. The current vaccination schedule is as follows: a first dose at the age of 12 months (or at nine months for children attending nurseries) and a second dose for children between the age of 13 and 24 months [4]. Catch-up immunisation for those born after 1980 was introduced in 2005 [5], and since February 2011, it has been recommended that all those born after 1980 receive two doses of combined measles-mumps-rubella (MMR) vaccine for full protection [6].

Within the framework of the measles elimination policy followed in the World Health Organization European Region since 1998 [7], a measles elimination plan was launched by the French Ministry of Health in 2005 [5]. This plan, updated by a circular in 2009 [8], reinstated measles on the list of notifiable diseases and described the preventive measures to be implemented when there was a case or a cluster of measles cases. Persons who have been in contact with a measles case and who are not vaccinated against measles should be vaccinated within $72 \mathrm{~h}$ of exposure. For some categories of people seen too late to be vaccinated or who cannot be vaccinated, it is recommended that they receive human polyvalent intravenous immunoglobulins after laboratory (virological) confirmation of the contact case, within six days after exposure. The categories are the following:

- unvaccinated pregnant women without a history of measles;

- immunocompromised patients, regardless of their vaccination status and measles history;

- children under the age of six months whose mother has measles;

- children under the age of six months whose mother has no history of measles and is not vaccinated;

- children between 6 and 11 months, not vaccinated against measles within $72 \mathrm{~h}$ of exposure, regardless of the vaccination status and measles history of the mother.

Despite the efforts towards elimination, measles outbreaks have become more frequent in France since January 2008, with the highest epidemic peak occurring in 2011 (604 cases notified in 2008, 1,544 in 2009, 
5,071 in 2010, 14,966 in 2011 and 728 between January and July 2012), and have resulted in 10 deaths [9]. This situation is linked to the insufficient vaccine coverage and to the existence of communities of susceptible people in which the virus circulates actively $[10,11]$.

Since the implementation of the measures to fight measles in France, there have not been any field evaluations. The objectives of the present survey were to quantify the number of patients who had received prophylactic immunoglobulins after exposure to a measles case, to describe basic characteristics of these patients and to study the application of the recommendations related to the delay of post-exposure and the laboratory confirmation of the contact cases.

\section{Methods}

The case definition of measles used in this survey was the one recommended by the World Health Organization [12]: any person in whom a clinician suspects measles infection or any person with fever and maculopapular rash and cough, coryza or conjunctivitis. Since the delivery of immunoglobulins must be done at a hospital, this survey was conducted in hospital pharmacies in metropolitan France. The French National Council of the Order of Pharmacists provided us with a file containing the names of the department heads of pharmacies in major and minor hospitals (not local ones). We added to this list further pharmacies using information from the French hospital federation (FHF, www.fhf.fr). After having excluded psychiatric hospitals, we had a list of 368 pharmacies to contact. Each pharmacy received a letter, a file explaining the aims of the study, and a questionnaire containing six questions and a table to fill out. The study targeted immunoglobulin delivery between 1 January 2010 and 31 August 2011. The following items were included in the survey: type of hospital and geographical location, delivery of prophylactic immunoglobulins after exposure to measles during the study period; if applicable, the number of doses delivered; supply difficulties for immunoglobulins during the study period; if applicable, the precise period during which supply difficulties were experienced. If they had delivered immunoglobulins, the pharmacists, assisted by physicians if necessary, provided the following information for each case: date of immunoglobulin delivery, age and sex of the patient, category of the patient (child under the age of six months, child between 6 and 11 months, pregnant woman, immunocompromised patient, other), measles vaccination status and number of doses, delay between the exposure and immunoglobulin delivery, laboratory confirmation of the contact case when the immunoglobulins were delivered, type of laboratory confirmation, and measles infection of the mother for children under the age of six months. The survey was sent by post on 26 October 2011. An email reminder was sent between 22 and 24 November 2011. The final deadline for answers was 1 December 2011. The results were analysed using Excel 2010 and R2.13.1 softwares. For quantitative variables, results are presented as mean \pm standard deviation.

\section{FIGURE 1}

Time pattern of immunoglobulin deliveries in metropolitan France $(n=400)$ and number of notified measles cases in France $(\mathrm{n}=19,335), 1$ January 2010 to 31 August 2011

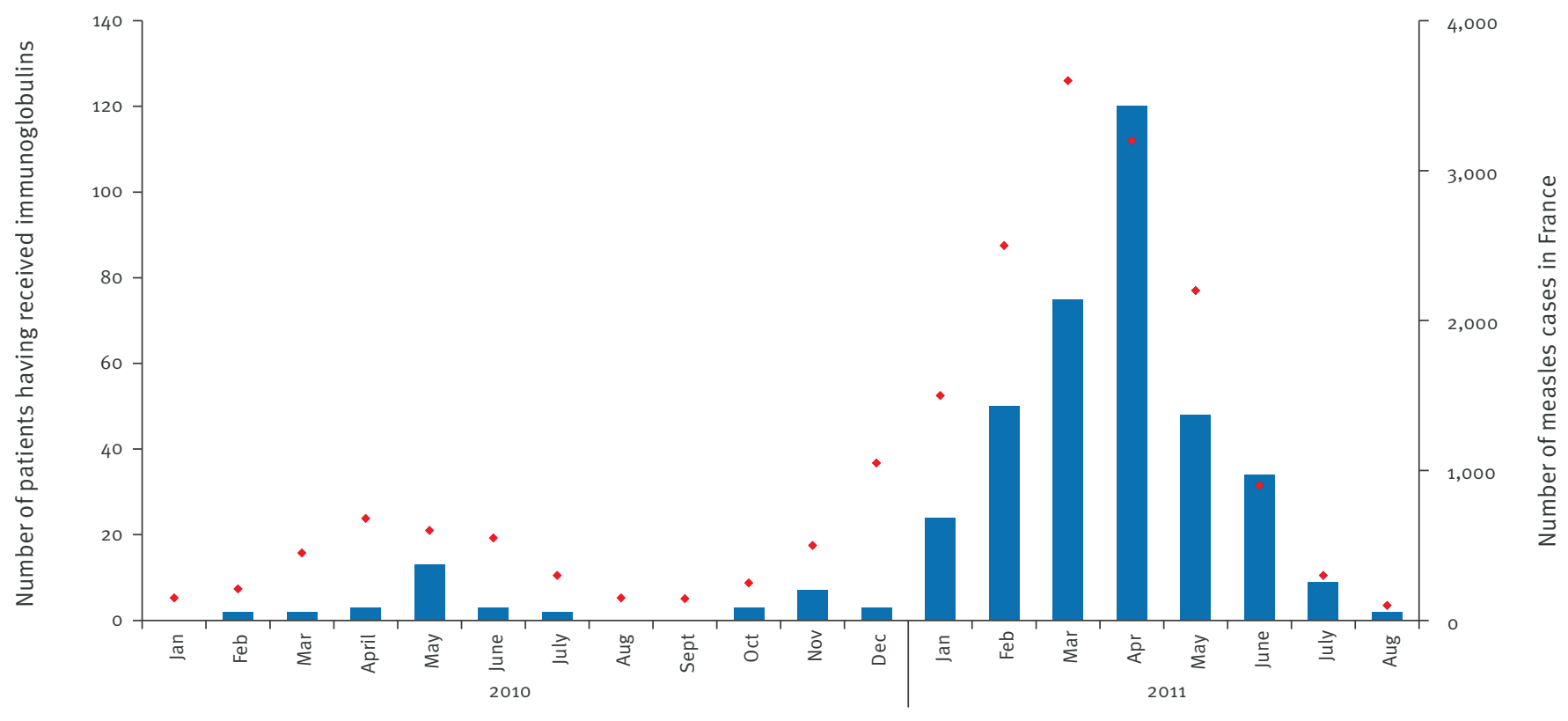




\section{FIGURE 2}

Geographical distribution of patients receiving prophylactic immunoglobulins after exposure to measles, metropolitan France, 1 January 2010 to 31 August 2011 $(\mathrm{n}=400)$

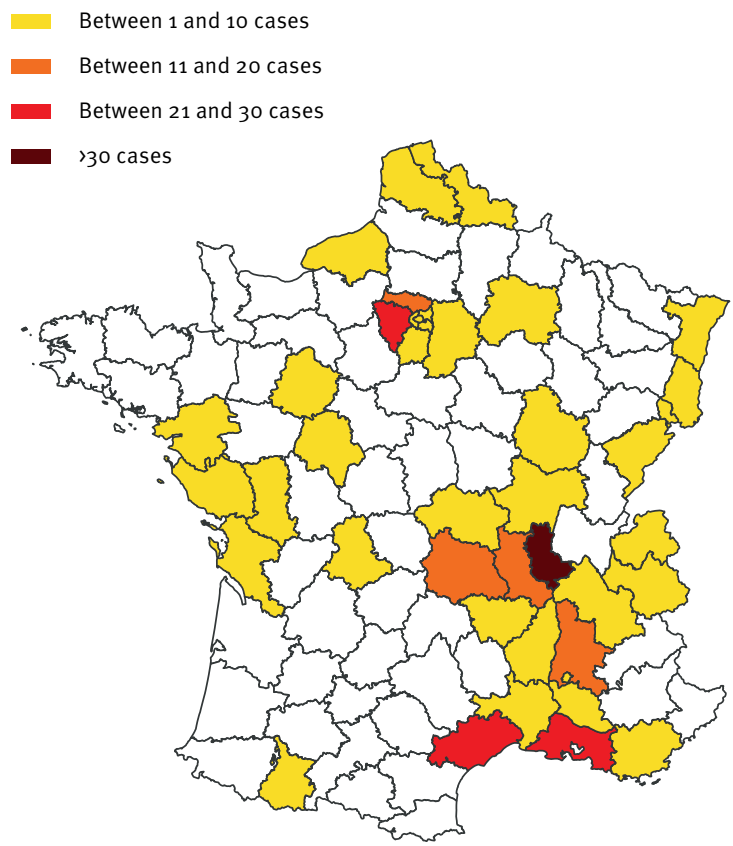

Note: Départements in white did not deliver immunoglobulins following exposure to measles.

\section{Results}

In total, 267 of 368 pharmacies replied to the survey, a response rate of $73 \%$. For 13 hospitals or hospital groups, we received joint responses for several (between two and four) pharmacies linked to these structures. The 267 pharmacies therefore belonged to 246 hospitals located in 92 (of 96) geographical Départements of metropolitan France (data not shown).

Of 246 hospitals, 55 (22\%) delivered prophylactic immunoglobulins after exposure to measles during the study period (1 January 2010 to 31 August 2011). Among the 55 hospitals delivering immunoglobulins, 34 were hospital centres and 21 university hospitals. In total, 400 patients received immunoglobulins. The mean number of immunoglobulins delivered per hospital was $7.3 \pm 22.4$ (range: $1-166$ ), $4 \pm 0.8$ for hospital centres (range: $1-20$ ) and $12.3 \pm 7.4$ for university hospitals (range: 1-166).

Most deliveries occurred between March and May 2011 (Figure 1). This pattern is very similar to that of the measles epidemic in France, which peaked in March to April 2011.
Some geographical areas in France were more affected than others: the Paris region, the northern region, the Atlantic coast, the eastern and the south-eastern regions (Figure 2). Immunoglobulin delivery was highest in the Rhône Département with 166 doses (42\%). This pattern is consistent with the geographical distribution of notified measles cases over the same time period, with a concentration of the cases in southeastern France, in Paris and to a lesser extent along the Atlantic coast $[13,14]$. This geographical distribution was independent of the number of answers per Département (data not shown).

The age of the patients ranged between one day and 86 years (Figure 3). Of 400 patients, 172 were children under the age of six months, and 55 were between 6 and 12 months-old. These two age categories represented more than $55 \%$ of the cases. The third most represented age group were the 26 to 30 year-old adults, with 25 cases (6.3\%). Among our patients, $24 \%$ were older than 30 years. Over the same time period, the age group for which most measles cases were notified in France were children under the age of one year (incidence: $140 / 100,000$ cases, representing $7 \%$ of the notified measles cases) and young adults between 15 to 19 years (incidence: 60/100,000 cases, representing $17 \%$ of the cases) $[13,14]$. Adults older than 30 years represented $12 \%$ of the notified measles cases (incidence less than $2 / 100,000$ cases).

)

Possible categories based on French recommendations were "children under six months-old", "children between 6 and 11 months-old", "pregnant women", "immunocompromised persons" or "others" [6]. These categories were not mutually exclusive so that, for instance, a nine month-old immunocompromised child

\section{FIGURE 3}

Age distribution of patients receiving prophylactic immunoglobulins following exposure to measles, metropolitan France, 1 January 2010 to 31 August 2011 $(n=400)$

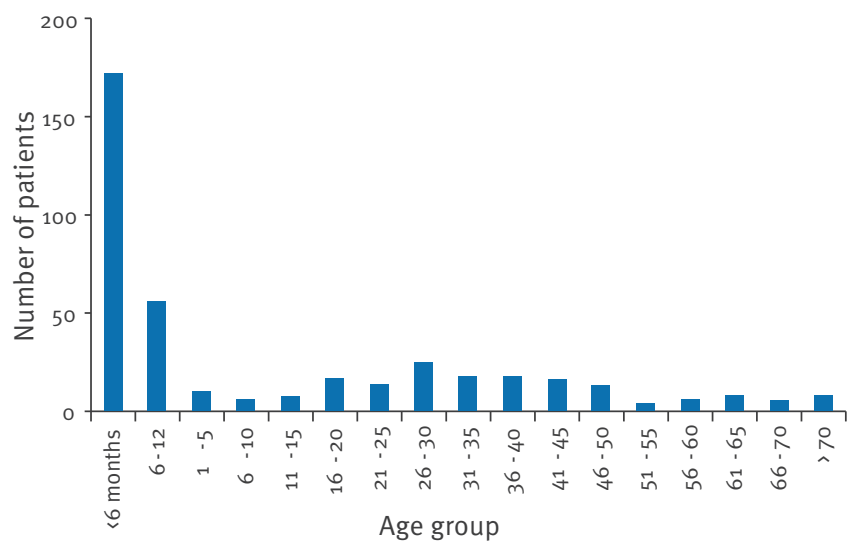




\section{FIGURE 4}

Estimated delay between the exposure to measles and the administration of prophylactic immunoglobulins, metropolitan France, 1 January 2010 to 31 August 2011 $(n=243)$

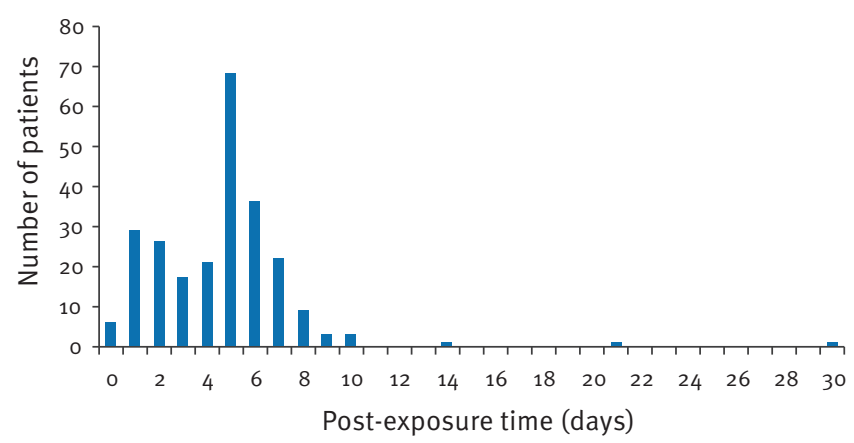

Note: Only precise answers are presented in this figure.

was counted in both categories "children between 6 and 11 months-old" and "immunocompromised persons". In our survey, 172 cases (42\%) were children under six months-old, 55 (14\%) were children between 6 and 11 months-old, 47 (12\%) were pregnant women, $120(29 \%)$ were immunocompromised persons, seven (1.7\%) were others, and there were seven with missing data (1.7\%). Eight patients belonged to two categories: "children under six months-old" and "immunocompromised persons".

The mean delay between exposure and immunoglobulin delivery was 4.6 days (range: 0-30 days). The median was five days. The most frequent delays were five and six days (Figure 4). There were 146 cases of missing data and 11 imprecise responses for this variable ( $n=157$ in total, i.e. $39 \%$ of the cases). This low response rate underlines the difficulty of estimating the post-exposure delay. Among the 11 imprecise answers, seven were precise enough to be categorised either as delay of six days or less, or as delay of more than six days. Of these 250 answers, $84 \%$ of administrations $(n=209)$ occurred within six days after exposure, as recommended. Three cases of very late immunoglobulin delivery $(14,21$ and 30 days after exposure) were observed (Figure 4). In one case, the pharmacist (and/ or physician) identified the rash as the beginning of the exposure (added as a comment in the answer).

Data regarding the laboratory (virological) confirmation of the contact case was also missing frequently, in $191(48 \%)$ of the cases. In the 209 responses received, $52 \%$ of the contact cases $(n=109)$ were declared as laboratory-confirmed at the time the immunoglobulins were delivered. When there had been a laboratory confirmation, the type of confirmation was requested in the questionnaire. The declared types of confirmation are described in Table 1. In eight cases declared as laboratory-confirmed, the type of confirmation written in the questionnaire was the rash, meaning that for these cases, the diagnosis was made using clinical signs, without laboratory confirmation. In three cases, the declared type of laboratory confirmation was rash+ELISA, meaning that the rash was used as clinical confirmation and the ELISA as the laboratory confirmation. In one case, the declared type of laboratory confirmation was salivary sample, which was an imprecise answer explaining what kind of sampling was done but not the laboratory test performed (both PCR and ELISA could have been done using the salivary sample). Consequently, removing the eight cases clinically confirmed based solely on the rash, only 101 cases (48\%) were laboratory-confirmed at the time the immunoglobulins were delivered. These 101 cases include those for whom the type of confirmation was not specified, assuming they were likely to have been confirmed by laboratory methods. In 48 additional cases, the laboratory confirmation of the contact case arrived a few days after the administration of the immunoglobulins (this information had been added as a comment in the answers).

In Table 2, results are presented by patient category. The eight immunocompromised children under the age of six months were counted in both categories "children aged under six months" and "immunocompromised persons". The seven responses with missing data for the patient category do not appear in this Table. The eight cases declared as laboratory-confirmed but only clinically confirmed based on the rash were considered as unconfirmed in the following analysis (six were children under six months-old and two were children between 6 and 11 months-old).

\section{TABLE 1}

Declared type of laboratory confirmation for contacts of people receiving anti-measles immunoglobulins, metropolitan France, 1 January 2010 to 31 August 2011 ( $\mathrm{n}=109)$

\begin{tabular}{|l|c|c|c|c|c|c|c|} 
& PCR & ELISA & PCR+ELISA & Rash & Rash+ELISA & Salivary sample & NA \\
\hline Number & 40 & 40 & 2 & 8 & 3 & 1 & 15 \\
\hline Percentage & 37 & 37 & 1.8 & 7.3 & 2.8 & 0.9 & 14 \\
\hline
\end{tabular}


Sex ratio, post-exposure delay (mean and percentage of post-exposure delay less or equal than six days) and contact case confirmation by patient category, metropolitan France, 1 January 2010 to 31 August $2011(\mathrm{n}=393)$

\begin{tabular}{|c|c|c|c|c|c|}
\hline & $\begin{array}{l}\text { Children aged } \\
\text { under six months } \\
(n=172)\end{array}$ & $\begin{array}{l}\text { Children aged } \\
\text { between } 6 \text { and } 11 \\
\text { months }(n=55)\end{array}$ & $\begin{array}{l}\text { Pregnant women } \\
\qquad(\mathrm{n}=47)\end{array}$ & $\begin{array}{l}\text { Immunocompromised } \\
\text { persons }\end{array}$ & $\begin{array}{l}\text { Others } \\
(\mathrm{n}=7)\end{array}$ \\
\hline Sex ratio (male/female) & $0.59(102 / 70)$ & $0.49(27 / 28)$ & - & $0.58(69 / 51)$ & $0.29(2 / 5)$ \\
\hline $\begin{array}{l}\text { Mean post-exposure delay in days } \\
(\min / \max )\end{array}$ & $\begin{array}{c}4.1 \pm 2.2 \\
(0 / 10) \\
\end{array}$ & $\begin{array}{l}5.6 \pm 4 \cdot 3 \\
(1 / 30)\end{array}$ & $\begin{array}{c}5 \cdot 5 \pm 0.3 \\
(1 / 8)\end{array}$ & $\begin{array}{l}4.1 \pm 3.7 \\
(0 / 21)\end{array}$ & $\begin{array}{c}6.6 \pm 0.4 \\
(0 / 7)\end{array}$ \\
\hline \multicolumn{6}{|l|}{ Post-exposure delay $\leq 6$ days $\%$ (n) } \\
\hline Yes & $70.9(122)$ & $58.2(32)$ & $46.8(22)$ & $32.5(39)$ & $14.3(1)$ \\
\hline No & $8.1(14)$ & $23.6(13)$ & $4.3(2)$ & $6.7(8)$ & $57.1(4)$ \\
\hline Not available & $20.9(36)$ & $18.2(10)$ & $48.9(23)$ & $60.8(73)$ & $28.6(2)$ \\
\hline \multicolumn{6}{|c|}{ Laboratory confirmation of the contact case \% (n) } \\
\hline Yes & $20.9(36)$ & $40.0(22)$ & $29.8(14)$ & $25.0(30)$ & $57.1(4)$ \\
\hline No & $44.2(76)$ & $20.0(11)$ & $6.4(3)$ & $16.7(20)$ & $\mathrm{o}(\mathrm{o})$ \\
\hline Not available & $34.9(60)$ & $40.0(22)$ & $63.8(30)$ & $58.3(70)$ & 42.9 (3) \\
\hline
\end{tabular}

a The sex ratio corresponds to the number of men (or boys) divided by the total number of patients.

There were more men (or boys) among the children aged under six months and among the immunocompromised persons and more women in the category "others". The mean post-exposure delay in the different groups ranged from 4.1 days to 6.6 days. The delay was the smallest among children under the age of six months and among immunocompromised persons. In three cases, immunoglobulins were delivered very late (14 and 21 days after exposure for two immunocompromised persons and 30 days after exposure for one child between 6 and 11 months-old). To evaluate adherence to recommendations, we analysed this variable using two categories: post-exposure delay of six days or less (as recommended) and post-exposure delay more than six days (Table 2). Many responses were lacking data for this new variable, especially for immunocompromised persons (61\%) and pregnant women (49\%). The category for which most administrations occurred within six days after exposure was "children aged under six months". The category in which most administrations occurred more than six days after exposure was "others" (four of seven cases), but there were very few cases in this category. It was followed by "children aged between 6 and 11 months", with 13 of 55 cases. However, for eight of these 13 cases, immunoglobulins were delivered seven days after exposure (data not shown).

Regarding laboratory confirmation of the contact case, missing data ranged from $35 \%$ for children aged under six months to $64 \%$ for pregnant women. The percentage of confirmed cases was highest for the category "others", but because of the low number of cases in this category, we cannot consider this percentage as representative. For the category "children aged under six months", 76 of 172 cases (44\%) were unconfirmed. Among the 172 children aged under six months, 27 $(16 \%)$ were less than one week-old, and 10 were newborns. For the 112 cases for whom the origin of the exposure was known, exposure came from family members (including the mother) in $60 \%$ of the cases $(n=66)$. Other cases were exposed through medical staff $(n=45$, i.e. $40 \%)$ or a nanny $(n=1$, i.e. $0.9 \%)$. Among pregnant women, the two most affected age groups were the 26-30 year-olds and the 31-35 yearolds (data not shown).

Among all 400 patients, we identified 10 children who possibly should have been vaccinated (children aged between 6 and 11 months for whom the post-exposure delay was three days or less) and one pregnant women who should not have received immunoglobulins (she had received two vaccination doses). The recommendations were not followed for these patients, but their medical conditions may have influenced the decision to deliver immunoglobulins.

\section{Discussion}

This survey permitted an assessment of immunoglobulin delivery as post-exposure prophylaxis in the event of contact with measles between 1 January 2010 and 31 August 2011. We counted 400 administrations during the study period, with most cases being children under the age of one year.

The response rate of $73 \%$ was satisfactory for a postal survey. We could not contact every hospital pharmacy in metropolitan France because the French National 
Council of the Order of Pharmacists did not provide an exhaustive list. According to the French hospital federation, there are 571 hospitals in metropolitan France (including major and minor hospitals, not local ones) [15]. Therefore, we contacted $65 \%$ of French major and minor hospitals but no local hospitals. However, we sent the questionnaire to $80 \%$ of France's major hospitals, which are more likely to deliver immunoglobulins in the studied indications. Therefore, we consider our study to be representative.

One of the objectives of this survey was to describe characteristics of patients having received prophylactic immunoglobulins following exposure to a measles case. The recommendations related to preventive measures to be implemented in the event of a measles case or cluster had been issued in 2005 and updated in 2009 and thus predated the current epidemic in France. Since then, no evaluation of the application of this measure has been conducted. With the current epidemic, basic information on post-exposure delay and percentage of confirmed contact cases could be important for decision makers in planning awareness campaigns or adapting recommendations. We therefore opted for a simple questionnaire, excluding questions about clinical diagnosis, the quantity of immunoglobulins delivered or patient evolution, so as to achieve a good response rate.

Consequently, we describe here the basic characteristics of the patients affected by these prophylactic measures. These data complement those obtained by notification, describing cases exposed to measles. The characteristics of the patients were different from those with a measles infection. Firstly, children under the age of one year, who are the age group most affected by measles infection, were proportionally even more represented among those receiving prophylaxis. Secondly, the most represented age group for adults receiving prophylaxis were the 26 to 30 yearolds, while the adult group most affected by measles infection are the 15 to 19 year-olds. Lastly, the age range of people affected by the prophylactic measures was wider than the age range of measles cases. This is linked to the categories of people for whom immunoglobulin delivery was recommended in this indication.

As previously stated, children under the age of one year were the most affected, especially very young children. Measles in infants can be very dangerous, and complications are very frequent in this age group (diarrhoea, otitis media, pneumonia, increased risk of encephalitis and panencephalitis, etc.) [1]. There are still cases of measles among women giving birth, which puts newborns at risk for subacute sclerosing panencephalitis, a fatal disease that manifests months or years after exposure [16]. Most children aged under six months for whom the source of exposure was known, were exposed by family members or medical staff. It is therefore crucial to increase awareness of measles among parents and medical staff [17]. Information campaigns directed towards women of child-bearing age or future parents could be useful in reducing the number of cases among pregnant women and newborns. Awareness campaigns could also be organised for medical staff working with immunocompromised persons.

Our results regarding temporal and geographic pattern are consistent with data from the French Institute for Public Health Surveillance (InVS) on the measles epidemic in France [9] which also show a concentration of the cases in south-eastern France. To address the concentration in this area, specific local actions might be useful. The incidence peak of immunoglobulin administrations occurred in March and April 2011, as did the incidence peak of measles cases. Since 2008, the epidemic has increased each year until 2011 and slowed down in 2012. Despite the decrease in the number of cases in 2012, authorities should continue promoting measles vaccination to control the spread of measles and end this epidemic.

The second objective of this survey was to describe practices related to post-exposure delay and laboratory confirmation of contact cases. The recommendation regarding the timing of immunoglobulins delivery was well followed: most administrations occurred within six days after exposure. However, a large proportion of the responses had missing or imprecise data for this question, highlighting the difficulty to estimate this post-exposure delay. In at least one case, the pharmacist (and the doctor) took the appearance of the rash as the beginning of exposure. Yet the contagious period usually begins five days before appearance of the rash, making it more difficult to estimate the beginning of exposure. In three cases, the immunoglobulins were delivered very late $(14,21$ and 30 days after exposure). The efficiency of immunoglobulins decreases strongly after six days following exposure. At this point, exposed persons would already be sick if they were infected by measles. Additional explanations regarding the inefficiency of immunoglobulins after six days of exposure might have to be added to the current recommendations.

Only half of the contact cases were laboratory-confirmed when the immunoglobulins were delivered. However, in 48 cases, the results of laboratory analyses were known a few days after immunoglobulin delivery, demonstrating the willingness of hospital teams to confirm contact cases. In these situations, the immunoglobulins must have been delivered for medical reasons justifying the absence of results. As this prophylactic measure concerns fragile persons who cannot be vaccinated after exposure, the precautionary principle may have prevailed in order to avoid potentially severe complications. For the category "children aged under six months", $44 \%$ of the contact cases were not laboratory-confirmed at the time the immunoglobulins were delivered. The short mean post-exposure delay of 4.1 days is consistent with the hypothesis of rapid delivery to avoid complications. A more precise 
survey with access to medical files could identify the reasons for immunoglobulin delivery in the absence of laboratory results. One of the reasons could be delays in running the laboratory analyses. Furthermore, during an epidemic like the current one in France, the positive predictive value of clinical diagnosis is quite good, so that not every contact case requires confirmation. Recommendations were made before the current outbreak, when the number of measles cases was low. In light of the current measles epidemic, these recommendations may need to be updated.

The results obtained in our survey on the characteristics of persons affected by anti-measles prophylaxis and of the pattern of exposure will help implementing actions targeted at specific categories of the population to control measles epidemic in France. The description of the post-exposure delay and of the percentage of contact cases confirmed may be useful for decision makers in adapting the recommendations to the current situation.

\section{Acknowledgements}

This work was conducted during an internship at the High Council for Public Health (HCSP, www.hcsp.fr). I would like to thank Roger Salamon, HCSP's president, Renée Pomarède, HCSP's general secretary, and members of the HCSP, for their warm welcome and their support for this study. My sincere gratitude also goes to Frédérique Pothier of the National Council of the Order of Pharmacists for her assistance and to Christian Perronne and Tamara Giles-Vernick for their valuable comments on this article. Finally, I would like to express my appreciation to all hospital personnel participating in this study, since without their assistance, the study would not have been possible.

\section{References}

1. Moss WJ, Griffin DE. Measles. Lancet. 2012;379(9811):153-64.

2. Sabella C. Measles: not just a childhood rash. Cleve Clin J Med. 2010;77(3):207-13.

3. Perry RT, Halsey NA. The clinical significance of measles: a review. J Infect Dis. 2004;189 Suppl 1:S4-16.

4. Baudon C, Parent du Chatelet I, Antona D, Freymuth F, Poujol I, Maine C, et al. Caractéristiques de l'épidémie de rougeole démarrée en France depuis 2008 : bilan des déclarations obligatoires pour les cas survenus jusqu'au 30 avril 2011. [Characteristics of the ongoing measles outbreak since 2008 in France: review of mandatory reported for cases occurred before 30 April 2011]. BEH nº33-34/2011. French. Available from: http://www.invs.sante.fr/Publicationset-outils/BEH-Bulletin-epidemiologique-hebdomadaire/ Derniers-numeros-et-archives/Archives/2011/BEH-n-33-34-2011

5. Plan d'élimination de la rougeole et de la rubéole congénitale en France 2005-2010. [Plan for the elimination of measles and congenital rubella in France 2005-2010]. Paris: Ministère de la Santé et des Solidarités; June 2005. French. Available from: http://www.sante.gouv.fr/IMG/pdf/plan_elimination_rougeole. pdf

6. Avis relatif à l'actualisation des recommandations vaccinales contre la rougeole pour les adultes. [Notice regarding updating the vaccine recommendations against measles for adults]. Paris: Haut Conseil de la Santé Publique; Feb 2011. French. Available from: http://www.hcsp.fr/docspdf/avisrapports/ hcspa20110211_rougeoleadultes.pdf

7. Health 21. The Health for all policy framework for the WHO European Region. Copenhagen: World Health Organization Regional Office for Europe; 1999. European Health for All series, No6, pp. 43-54. Available from: http://www.euro.who. int/_data/assets/pdf_file/o010/98398/wa540ga199heeng. pdf

8. Circulaire $\mathrm{N}^{\circ} \mathrm{DGS} / \mathrm{RI} 1 / 2009 / 334$ du 4 novembre 2009 relative à la transmission obligatoire de données individuelles à l'autorité sanitaire en cas de rougeole et la mise en oeuvre de mesures préventives autour d'un cas ou de cas groupés. [Circular No. DGS/RI1/2009/334 of 4 November 2009 concerning the compulsory transmission of personal data to the health authority in case of measles and the implementation of preventive measures around a case or cluster of cases]. Paris: Ministère de la Santé et des Sports; Nov 2009 . French. Available from: http://www.sante.gouv.fr/ IMG/pdf/o9 334topdf.pdf

9. Rougeole. Points d'actualités. Données provisoires à la date de l'analyse. [Measles. News. Preliminary data at the time of analysis]. Paris: Institut de Veille Sanitaire; 8 Aug 2012. French. Available from: http://www.invs. sante.fr/Dossiers-thematiques/Maladies-infectieuses/ Maladies-a-prevention-vaccinale/Rougeole/Points-d-actualites

10. Parent du Châtelet I, Antona D, Freymuth F, Muscat M, Halftermeyer-Zhou F, Maine C, et al. Spotlight on measles 2010: update on the ongoing measles outbreak in France, 2008-2010. Euro Surveill. 2010;15(36): pii=19656. Available from: http://www.eurosurveillance.org/ViewArticle. aspx?Articleld $=19656$

11. Muscat M. Who gets measles in Europe? J Infect Dis. 2011;204 Suppl 1:S353-65.

12. WHO recommended surveillance standard of measles. Geneva: World Health Organization. [Accessed: July, 2012]. Available from: http://www.who.int/immunization_monitoring/diseases/ measles_surveillance/en/index.html

13. Données de déclaration obligatoire de rougeole en France (antérieures au 1er juin 2012). [Mandatory reporting data of measles in France (prior to 1 June 2012)]. Paris: Institut de Veille Sanitaire; Jun 2012. French. Available from: http://sas. invs.sante.fr/SASStoredProcess/do?_program=/SAS $\% 20$ internet/PROD/rougeole/accueil\&_username=web@ saspw\&_password=pass4web

14. Institut de Veille Sanitaire. Epidémie de rougeole en France - Actualisation des données de surveillance au 5 octobre 2011. [Measles epidemic in France - Updated surveillance data on 5 October 2011]. Paris: Institut de Veille Sanitaire; Oct 2011. French. Available from: http://www.invs.sante.fr/ Dossiers-thematiques/Maladies-infectieuses/Maladies-aprevention-vaccinale/Rougeole/Points-d-actualites/Archives/ Epidemie-de-rougeole-en-France.-Actualisation-des-donneesde-surveillance-au-5-octobre-2011

15. Nombre de structures hospitalières publiques. [Number of public hospitals]. Paris: Fédération Hospitalière de France; French. Available from: http://etablissements.fhf.fr/annuaire/ statistiques.php?item $=$ structures

16. Garg RK. Subacute sclerosing panencephalitis. J Neurol. 2008;255(12):1861-71.

17. Bellini WJ, Rota JS, Lowe LE, Katz RS, Dyken PR, Zaki SR, et al. Subacute sclerosing panencephalitis: more cases of this fatal disease are prevented by measles immunization than was previously recognized. J Infect Dis. 2005;192(10):1686-93. 